\title{
A liquid crystal-based sensitive element for optical sensors of cholesterol
}

\author{
M.V.Vistak ${ }^{1}$, V.E.Dmytrakh ${ }^{1}$, Z.M.Mykytyuk ${ }^{2}$, \\ V.S.Petryshak ${ }^{2}$, Y.Y.Horbenko ${ }^{3}$ \\ ${ }^{1}$ D.Halytsky Lviv National Medical University, \\ 69 Pekarska Str., 79010 Lviv, Ukraine \\ ${ }^{2}$ Lviv Polytechnic National University, 12 S.Bandery Str., \\ 79013 Lviv, Ukraine \\ ${ }^{3}$ I.Franko National University of Lviv, 1 Universytetska Str., \\ 79000 Lviv, Ukraine
}

Received May 11, 2017

\begin{abstract}
Composites based on cholesteric-nematic mixtures of nematic 5CB and cholesteric BLO61 are proposed as active materials for cholesterol optical sensor.

Keywords: liquid crystal, optical sensor, cholesterol.

Предлагается использовать холестерико-нематическую смесь на основе нематического жидкого кристалла 5CB и холестерического жидкого кристалла BLO-61 в качестве чувствительного әлемента оптического сенсора холестерина.
\end{abstract}

Рідкокристалічний чутливий елемент для оптичних сенсорів холестерину. М.В.Вісьтак, В.Є.Дмитрах, З.М.Микитюк, В.С.Петришак, Ю.Ю.Горбенко.

Пропонується використати холестерико-нематичну суміш на основі нематичного рідкого кристала 5CB та холестеричного рідкого кристала BLO-61 у якості чутливого елемента оптичного сенсора холестерину.

\section{Introduction}

Among the main factors affecting the risk of cardiovascular diseases is the increased concentration of cholesterol in human blood. This makes monitoring of cholesterol in biological objects an important task [1]. Various types of biosensors have been developed for qualitative and quantitative determination of cholesterol levels. One of the promising ways is to develop optical sensors using liquid crystal (LC) materials for cholesterol detection. For example, under the influence of cholesterol molecules nematic liquid crystals (NLC) can change their molecular orientation from planar to homeotropic [2, 3].

Cholesterol $\left(\mathrm{C}_{27} \mathrm{H}_{46} \mathrm{O}\right)$ is an organic fatlike substance from the group of sterols, first isolated from brain tissue and bile. It is insoluble in water but soluble in organic solvents. Cholesterol is found in all body tissues and blood plasma. Cholesterol enters the human body from food and is absorbed well in the intestine only in the presence of bile. Normally, in human blood the cholesterol level amounts $150-200 \mathrm{mg} / \mathrm{ml}$. Under certain pathological changes in human body, the cholesterol concentration in blood can vary in either direction. With atherosclerosis or diabetes, the cholesterol level is increased significantly, while with the organism exhaustion and certain infectious diseases, it is reduced. In case of metabolic distortion, cholesterol and its derivatives would be deposited on the walls of blood vessels, causing the atherosclerosis. Excre- 
tion of cholesterol from bile in the crystalline state leads to a gallstone disease.

For precise monitoring of cholesterol levels in biological substances, the numerous studies are carried out with the aim to design chemical and biochemical sensors for analytical devices of qualitative and quantitative determination of cholesterol. Thus, Marazuela et al. proposed an optical sensor for monitoring the luminescence changes in ruthenium complex (II) as function of cholesterol concentration at $620 \mathrm{~nm}$ wavelength [4]. Law et al. determined the cholesterol level basing on the color changes of dyes after enzymatic reactions using the spectrophotometric method [5]. Oxidation of dyes such as 4-aminoantypiryn, o-dianizidin, 4-aminophenason and etc. are used for this aim. Other methods were also proposed, e.g., using immobilized cholesterol esterase and cholesterol oxidase [6,7], sputtered zinc oxide nanoporous thin films [8] or $\mathrm{N}$ (2-aminoethyl)-3-aminopropyl-trimethoxysi lane self-assembled monolayer [9]. Wu et al. used the fluorescence quenching of ruthenium complex (II) by oxygen molecules, with fluorescence increasing with the of cholesterol concentration [10]. Kouassi et al. determined the cholesterol concentration by means of registration of changes in absorption intensity for 4-cholestene-3-one in the enzymatic reaction by using the spectrophotometry [11]. In optical sensors the surface plasmon resonance effects can be used to design the cholesterol biosensor [12-14]. Martin et al. used the ratio between the changes in resonant frequency and correspondingly the change in mass for designed sensor on surface acoustic waves to determine the cholesterol concentration in real time [15].

Liquid crystals are promising new materials for sensors with advanced properties. Biosensors on the base of LC materials are of special interest due to their unique sensitive properties. The alignment of LC molecules is extremely sensitive to biomolecules and other chemicals, offering relatively easy procedures for conversion of minute composition changes into measurable optical signals, without application of electric voltage or molecular labels; in some cases, the optical signals can be easily recorded with the naked eye. These important characteristics of biosensors on the base of LC makes them promising for easy detection, high sensitivity and low-cost detection of biosubstances [16].
In $[2,3]$, cholesterol was detected by means of changing the orientation of 4-cyano-4pentylbiphenyl (5CB) LC from planar to homeotropic.

In [17], detection of free cholesterol molecules by changing the $\mathrm{pH}$ of the 5CB LC processed by ultraviolet (UV) radiation was reported. Basing on this method, the operative mechanism of cholesterol sensor was developed, monitoring the cholesterol concentrations in the 10 to $300 \mathrm{mg} / \mathrm{dl}$ range, which covers the physiologically relevant range in human body $(90-220 \mathrm{mg} / \mathrm{dl})$.

Another variant of LC cholesterol sensor was proposed in [18]. The operation of this sensor is based on changes in orientation of the LC molecules under the influence of cholesterol oxides (ChOx). This sensor can measure the concentration of cholesterol in the range of $10 \mathrm{mg} / \mathrm{dl}$ to $250 \mathrm{mg} / \mathrm{dl}$. In [19], the cholesterol biosensor operation was based on changing the orientation of LC molecules from homeotropic to planar in the presence of cholesterol. This transition was observed with a polarized optical microscope in crossed polarizers.

In this paper, we propose an active medium based on cholesteric-nematic mixtures (CNM), with detection of cholesterol by changes in selective reflection properties of the cholesteric sensor material.

\section{Experimental}

As a first step of our studies, we measured changes in the optical transmittance intensity of nematic LC 5CB and cholesteric (chiral nematic) LC BLO-61 versus cholesterol concentration by means of a USB-2000 spectrophotometer in the wavelength range of 250-800 $\mathrm{nm}$. The procedure of obtaining spectral characteristics and processing experimental data was described in our previous papers $[20,21]$.

The obtained results show that introduction of cholesterol to 5CB in concentrations up to $\sim 20 \%$ practically does not affect the transmission spectrum of the LC at room temperature. However, for BLO-61 the increased cholesterol concentration changes the recorded wavelength of minimum transmittance (Fig. 1).

As it can be seen from Fig. 1, the increase in the cholesterol concentration in BLO-61 from 0 to 5 wt. $\%$ results in a sharp change in the minimum transmittance wavelength (from 427 to $452 \mathrm{~nm}$ ). With higher cholesterol concentrations, the wavelength at minimum transmittance is stabilized. 


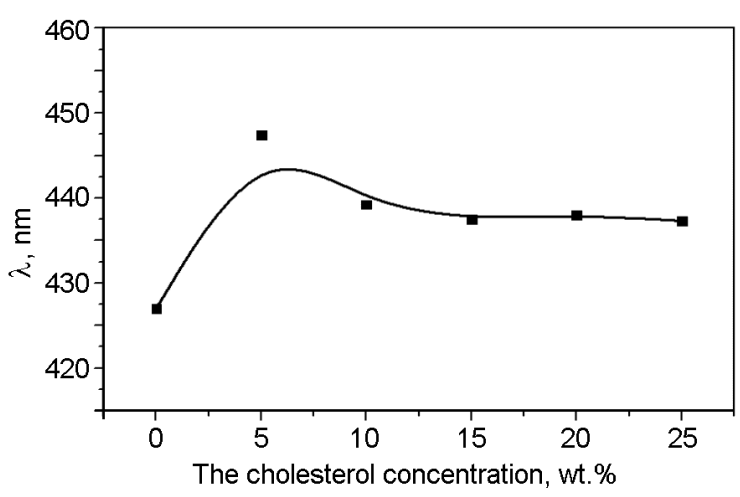

Fig. 1. Dependence of the wavelength of minimum transmittance for BLO-61 versus concentration of the cholesterol dopant.

For further investigation, we prepared cholesteric-nematic mixtures (CNM) of BLO61 and 5CB (20-40 wt.\% 5CB) with increments of 5 wt. $\%$. The nematic LC concentration was chosen to obtain the maximum of selective reflection (i.e., minimum of selective transmission) in the visible region of spectrum. The experimental composites were obtained by heating the components to temperatures $\sim 5-7^{\circ} \mathrm{C}$ above the phase transition to the isotropic state. Stirring the mixture was carried out by using a magnetic stirrer.

In the transmission spectra of the studied CNMs we observed two minimums of transmittance, one of which, at the wavelength of $320 \mathrm{~nm}$, corresponded to the absorption band of 5CB. The location of the second minimum depends on the nematic $5 \mathrm{CB}$ concentration in a CNM, with changes in 5CB concentration from 20 wt. $\%$ to 40 wt. $\%$ shifting the selective wavelength range from 460 to $660 \mathrm{~nm}$ [22].

To each of the formed CNMs, we added cholesterol in concentrations from 5 to 25 wt. $\%$. In Fig. 2, the obtained dependences of the minimum transmittance wavelength on cholesterol concentration are shown.

Taking into account the analysis of the minimum transmittance wavelength vs. cholesterol concentration plots shown in Fig. 2, it can be concluded that increasing of the cholesterol concentration in CNM from 0 to 5 wt. \% shifts the minimum transmittance towards the long-wavelength spectral range, with further increasing of the cholesterol concentration leads to stabilization of the measured optical signal.

\section{Results and discussion}

The sensitivity properties of these nanocomposites can be characterized by the spec-

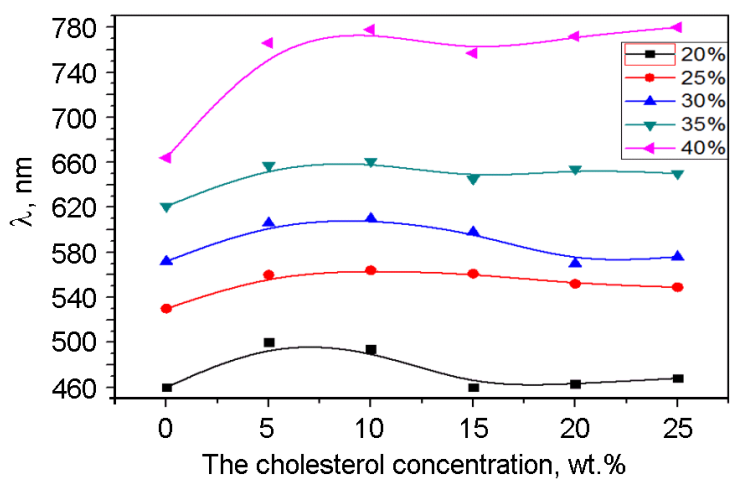

Fig. 2. Dependences of the wavelength of minimum transmittance versus cholesterol concentrations for BLO-61 + 5CB sensor nanocomposites.

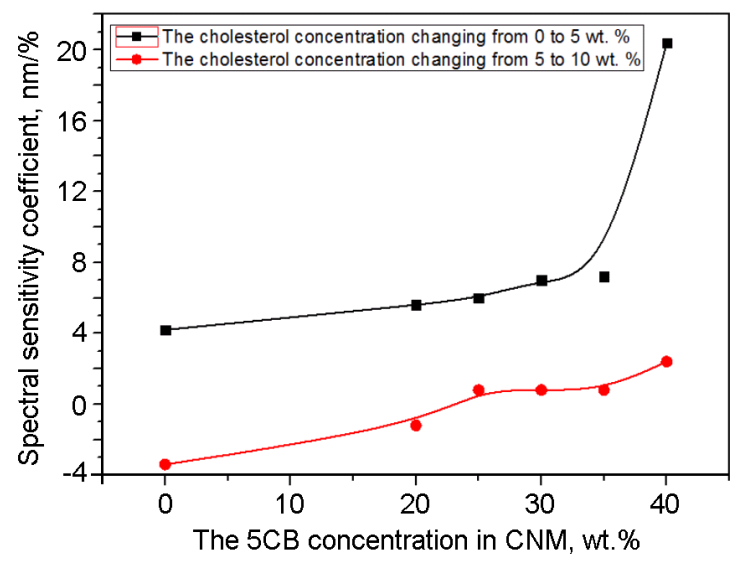

Fig. 3. Dependences of the spectral sensitivity coefficient to cholesterol of BLO- $61+5 \mathrm{CB}$ sensor composite vs. concentration of $5 \mathrm{CB}$ in

tral sensitivity coefficient $S$, defined by the ratio $S=\Delta \lambda / \Delta C$, where $\Delta \lambda$ is the deviation of the minimum transmittance wavelength of CNM, $\mathrm{nm}$ (depending on the cholesterol concentration in $\mathrm{CNM}$ ), and $\Delta C$ is the change in cholesterol concentration, \%. If we change the cholesterol concentration from 0 to 5 wt.\%, an approximately linear region can be observed in Fig. 2. From this region, the spectral sensitivity values for each CNM and for pure CLC BLO-61 are determined. For pure BLO-61 the spectral sensitivity coefficient is $4.2 \mathrm{~nm} / \mathrm{wt} . \%$. With CNMs, this ratio increases with the increasing concentration of nematic 5CB in CNM, and the coefficient of spectral sensitivity at 40 wt. $\%$ of $5 \mathrm{CB}$ amounts to $20.4 \mathrm{~nm} / \mathrm{wt} . \%$. The dependence of the spectral sensitivity coefficient to cholesterol versus 5CB concentration in the CNM is shown in Fig. 3. So, we can suggest that the best sensor composite is CNM with 5CB con- 


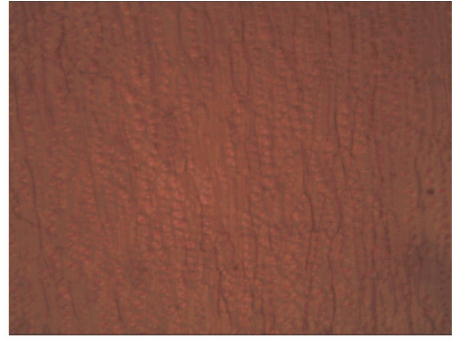

$5 \%$

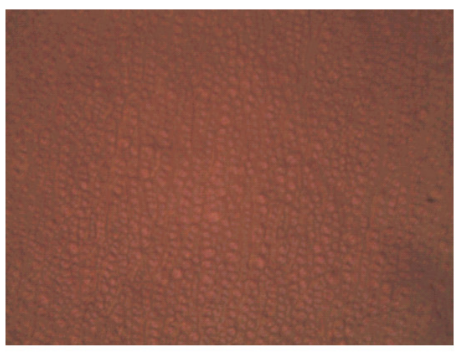

$10 \%$

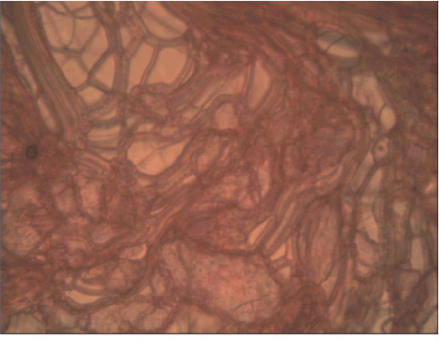

$15 \%$

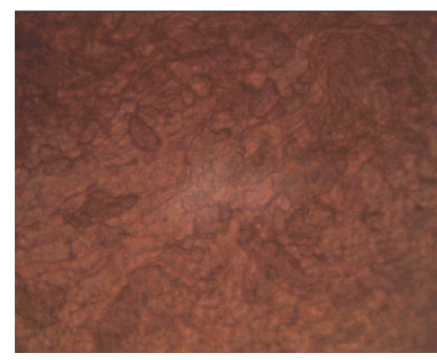

$20 \%$

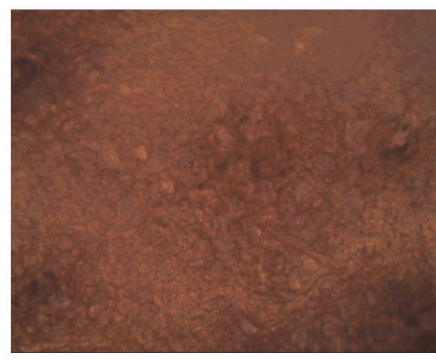

$25 \%$

Fig. 4. The microphotographs of CNM sensor composites at different concentration of cholesterol.

centration of $40 \mathrm{wt.} \%$, because of the highest spectral sensitivity coefficient.

To evaluate the morphology of the investigated composites, the pictures of CNM with cholesterol concentrations from 0 to 25 wt. \% were obtained using a MicroMed Microscope XS-5520 microscope (at 40x magnification) equipped with a MicroMed Mega Cmos 3.0 webcam (Fig. 4). In the CNMs, some changes in morphology are observed upon changing the cholesterol concentration, but these changes still correspond to the cholesteric structure, with no changes in the phase state or substantial non-homogeneity observed. Let us analyze the mechanism of interaction of cholesterol with the multi-component chiral liquid crystal mixture.

For CNM with cholesterol at increasing cholesterol concentrations, the shifts of the minimum optical transmittance (maximum optical density) toward longer wavelengths are observed. Such a phenomenon can arise from contributions of atom groups with lone pair of electrons (e.g.,, -OH group present in the cholesterol molecule) that come into $p-\pi$ conjugation with multiple bonds. The carbonitrile group $(-\mathrm{C} \equiv \mathrm{N})$ in $5 \mathrm{CB}$ is electrophilic (there is a partial positive effective charge on carbon atom), so prone to reactions of nucleophilic addition.

The electrophile can react with compounds having an unshared electron pair. This suggests some interaction between the molecules of cholesterol and 5CB as a result of which the LC molecules can change their spatial characteristics (structure, spiral orientation, optical conformation), which in turn directly affects the location of minimum on the optical transmittance spectrum.

To interact with weak nucleophiles such as alcohols $\mathrm{ROH}$, nitrile group requires additional activation - protonation. The reaction of nucleophilic addition can schematically be presented at Scheme.

Scheme.

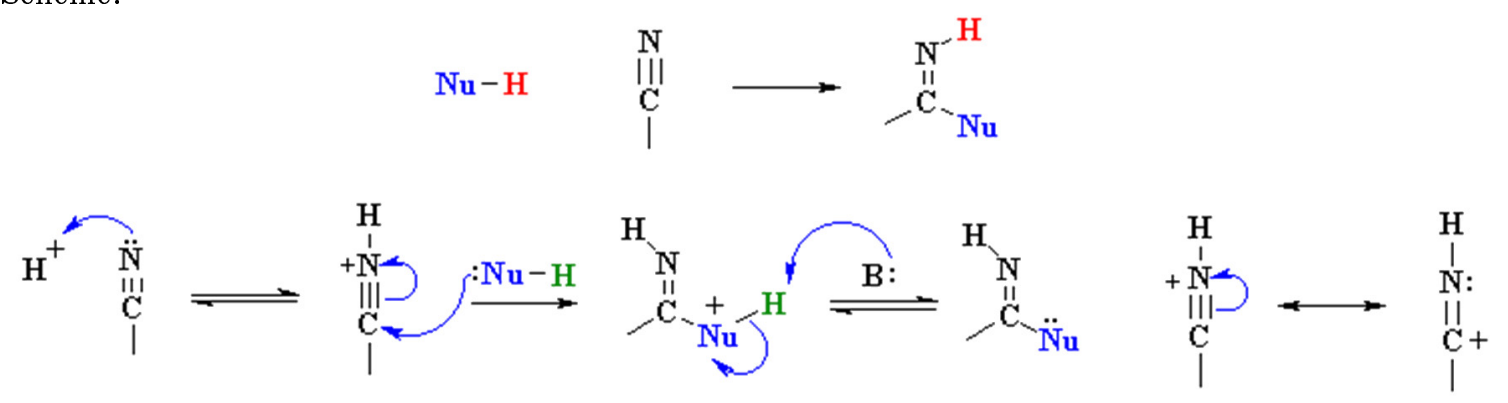


In [23], the nature of the interaction of 5CB with cholic acid, which is a product of oxidation of cholesterol, is analyzed, and the mechanism of complex formation between the molecules of liquid crystal 5CB and cholic acid is suggested. In our case, similar interactions between 5CB and cholesterol molecules result in the increased helical pitch in the cholesteric phase, manifested in the increased wavelength of minimum selective transmission.

\section{Conclusions}

In paper shown the CNM can be used as sensitive material for cholesterol optical sensor. Interaction with cholesterol leads to changes in spectral characteristics of CNM, with the wavelength of minimum transmittance shifted towards long-wavelength region of spectrum. Sensitivity characteristics of the obtained sensor material are determined, and a physico-chemical mechanism of interaction of $\mathrm{CNM}$ with cholesterol is proposed.

\section{References}

1. J.D.Brunzell, M.Davidson, C.D.Furberg et al., Lipoprotein management in patients with cardiometabolic risk: con-sensus statement from the American Diabetes Association and the American College of Cardiology Foundation, Diabetes Care 31, 811 (2008).

2. S.Munir, M.Khan, S.Y.Park, Sensor Actuat B:Chemical, 220, 508 (2015).

3. H.G.Lee, S.Munir, S.Y.Park, ACS Appl.Mat. Inter., 8, 26407 (2016).

4. M.D.Marazuela, B.Cuesta, M.C.Moreno-Bondi, A.Quejido, Biosens. Bioelectron., 12, 233 (1997).
5. W.T.Law, S.Doshi, J.McGeehan et al., Clin. Chem., 43, 384 (1997).

6. V.Malik, C.S.Pundir, Biotechnohem Appl. Bioc., 35, 191 (2002).

7. C.S.Pundir, Curr.Appl.Phys, 3, 129 (2003).

8. S.P.Singh, S.K.Arya, P.Pandey et al., Appl. Phys. Lett., 91, 063901 (2007).

9. S.K.Arya, A.K.Prusty, S.P.Singh et al., Anal. Biochem., 363, 210 (2007).

10. X.J.Wu, M.M.Choi, Anal.Chem., 75, 4019 (2003).

11. G.K.Kouassi, J.Irudayaraj, G.McCarty, $J$. Nanobiotechn., 3, 1 (2005).

12. S.K.Arya, P.R.Solanki, R.P.Singh et al., Talanta, 69, 918 (2006).

13. P.Pandey, S.P.Singh, S.K.Arya et al., Langmuir, 23, 3333 (2007).

14. P.R.Solanki, S.K.Arya, Y.Nishimura et al., Langmuir, 23, 7398 (2007).

15. S.P.Martin, D.J.Lamb, J.M.Lynch, S.M.Reddy, Anal.Chim.Acta., 487, 91 (2003).

16. M.Tyagi, A.Chandran, T.Joshi et al., Appl. Phys.Lett., 104, 154104 (2014).

17. Y.Wei, C.H.Jang, J.Mater.Sci., 50, 4741 (2015).

18. Po-Chin Nien, Po-Yen Chen, Kuo-Chuan Ho, Sensors, 9, 1794 (2009).

19. S.Munir, S.Y.Park, Anal.Chim.Acta, 893, 101 (2015).

20. O.Sushynskyi, M.Vistak, Z.Gotra et al., SPIE Photonics Europe. Intern. Soc. for Optics and Photonics (2014), p.91271F.

21. Z.Mykytyuk, A.Fechan, V.Petryshak et al., Modern Problems of Radio Engineering. Telecommunications and Computer Science (TCSET), 2016 13th Intern. Conf. IEEE (2016), p.402

22. V.Petryshak, Z.Mikityuk, M.Vistak et al., Prz. Elektrotechniczn., 93, 117 (2017).

23. Niu, D.Luo, R.Chen et al., Opt.Commun., 381, 286 (2016). 